\title{
Aportes para la gestión de la imagen institucional de los centros educativos
}

\author{
Contributions to the management of the \\ institutional image of educational centers
}

\begin{abstract}
Mariela Questa
Master en Gestión Educativa, Universidad ORT Uruguay. Licenciada en Relaciones Internacionales, Universidad de la República, Montevideo, Uruguay. Docente Comercio Exterior, Instituto Tecnológico CTC. Encargada de la Gestión Académica en Liceo San Juan Bautista de la Misericordia.
\end{abstract}

Fecha de recibido: 17/02/2014

Fecha de aceptación: 22/05/2014

\section{Resumen}

Este artículo surge como corolario de una investigación realizada en el marco del Máster en Gestión Educativa de la Universidad ORT Uruguay. Dicha investigación tuvo por objetivo diagnosticar a una institución educativa dedicada a la formación en carreras técnicas situada en el interior del país, que presenta dificultades para lograr un aumento en las matrículas.

Se trabajó con la metodología de estudio de caso, lo que implicó la selección de técnicas de investigación mixtas (tanto cualitativas como cuantitativas) para un mejor abordaje del objeto de estudio.

En el diseño de la investigación se proyectaron entrevistas, instancias de observación, análisis documental y encuestas, buscando complementar los puntos de vista de los actores institucionales implicados en la problemática con las opiniones de alumnos, egresados y desertores.

El análisis buscó contrastar las lógicas de funcionamiento institucional planteadas desde la dirección con la realidad de los alumnos y sus motivaciones. Esto posibilitó el acceso a los elementos subyacentes existentes y su importancia en la formación de la imagen del centro. El diagnóstico se desarrolló a partir de la aplicación de la técnica del iceberg y de la realización de una matriz FODA. Estas herramientas permitieron generar dos líneas o visiones del problema que posibilitaron diagramar la acción de mejora.

El principal hallazgo, sustentado en la revisión teórica de diferentes autores, determina que existe una interrelación entre la forma en que la oferta educativa se adapta a las necesidades del entorno y la comunicación de esta oferta al exterior de la organización con el nivel de matriculaciones.

La discusión para enriquecer estos contenidos parte de la falta de producción académica suficiente como para contrastar diferentes experiencias de gestión de la imagen de centros educativos. El objetivo de este artículo es generar un espacio de reflexión para que el tema de la imagen institucional se incluya en la agenda de los directivos.

PALABRAS CLAVE: imagen institucional, marketing educativo, gestión por procesos, desarrollo organizacional, calidad educativa. 


\section{Abstract}

This article comes as a corollary of a study conducted within the frame of the Master Degree in Educational Management at University ORT Uruguay. This research was aimed at diagnosing a Technical Training Institute located in the countryside, which was experiencing difficulties in achieving an increase in enrollment.

The work was based on case-study methodology, which involved the selection of techniques of mixed research (both qualitative and quantitative) for a better approach to the object of study.

In the design of the research, interviews, observation procedures, document analysis and surveys were planned, seeking to supplement the views of institutional stakeholders involved in the issue with the views of students, graduates and dropouts.

The analysis sought to contrast the logics of institutional operation coming from the Board with the reality of students and their motivations. This allowed access to the existing underlying elements and their importance in the center's institutional image. For the diagnosis, the iceberg technique was carried out as well as the conduction of the SWOT Matrix. Such tools allowed the creation of two lines or visions of the problem in order to outline the improvement action.

The main finding, supported by the review of theories from different authors, determined that there is a relationship between the way in which educational proposals are tailored to suit the needs of the environment and the spread of this proposal to the outside of the organization, with the level of enrollments.

The discussion to enrich these contents arises from the lack of sufficient academic production so as to contrast different experiences in image management of educational centers. The purpose of this article is to create a space for reflection so that the issue of institutional image is included on the Board's agendas.

KEYWORDS: institutional image, education marketing, process management, organizational development, educational quality.

\section{Introducción}

Pensar en educación muchas veces se limita a reflexionar desde un punto de vista arbitrario y sesgado: lo pedagógico, lo político, lo administrativo. Las tareas que se realizan en un centro educativo, las actividades anuales o semestrales muchas veces se tornan en una simple costumbre carente de significado específico, impuestas por un modelo educativo global y centradas en el logro de objetivos estadísticos.

Los directivos se ven agobiados por la burocracia administrativa y la evaluación externa que se transforma en un arma punitoria. Pocas veces se tiene oportunidad de plantear y trabajar sobre los cambios que necesita la institución. El conocimiento de los alumnos y de sus realidades particulares es inversamente proporcional al tamaño del centro.

Los docentes se ven obligados a seguir planes de estudios con temas que muchas veces no logran captar la atención de los alumnos por estar alejados de sus gustos y necesidades formativas.

Si bien existen sistemas educativos que tratan de despegarse de esta tendencia, y centros que trabajan para implantar la innovación y desarrollar las capacidades necesarias para que los alumnos integren con éxito los desafíos de aprendizajes requeridos por el siglo XXI, cabe preguntarse: ¿Cuál es la imagen que tienen los centros educativos en los educandos actuales? ¿Y en la sociedad? ¿Qué valor tiene actualmente la educación?

Ciertamente que los casos más exitosos se dan en aulas donde los alumnos son reconocidos por su singularidad y potenciados en sus capacidades individuales.

Haciendo una rápida búsqueda en la red, podemos encontrar blogs de docentes que comparten sus experiencias innovadoras, cientos de tweets diarios que dan cuenta de fórmulas de éxito para potenciar las distintas facetas del alumno, pero que generalmente dejan de lado una cuestión importante. ¿Están los centros educativos preparados para gestionar, como 
unidad, la enseñanza de calidad y dar a conocer su oferta formativa de manera tal que capte alumnos? ¿Qué ideas guía deben acompañar esta faceta de la gestión institucional? ¿Qué herramientas pueden utilizar los directivos para mejorar la imagen?

\section{El contexto del estudio}

La investigación que da lugar a estas reflexiones se desarrolló en un departamento (división político-administrativa del país) del Uruguay. La institución privada pertenece a una red de centros que brindan carreras técnicas en las áreas de administración e informática en asociación con una Universidad con sede en la capital del país (véase Tabla A).

La creación de la Red de centros en la década de los noventa fue motivada por la necesidad de descentralización de la educación, para atender a un grupo de personas que, viviendo en el interior del país, no deseaban o no podían acceder a la educación superior que se brinda de manera predominante en la capital del país. La demanda de capacitación en tecnicaturas se vio favorecida por la demanda de recursos humanos especializados en esas áreas de formación por parte de las empresas.

La institución estudiada representa un caso especial debido a que en el mismo departamento existen dos centros de iguales características, no habiendo otro caso en la Red. Esto se debe a las particularidades del departamento, que cuenta con varias ciudades importantes cercanas e interconectadas entre sí por un sistema de transporte rápido y fluido (basado en buses).

En este contexto, el centro tiene una amplia zona de influencia, cuenta con docentes capacitados y la infraestructura adecuada para este tipo de formación. A esto se suma la certificación que reciben los alumnos que finalizan las carreras, cuyos títulos son homologados por la Universidad, y los vínculos de la institución con las empresas de la zona, que permiten manejar una bolsa de empleo y la realización de pasantías. También se deben tener en cuenta los proyectos de apertura a la comunidad que desarrolla el centro, tales como charlas abiertas y gratuitas con expertos, convenios, alianzas con empresas y asociaciones, entre otros.

Tabla A. Características del centro objeto de estudio

\begin{tabular}{|l|l|}
\hline \multicolumn{2}{|c|}{ Centro Educativo } \\
\hline Tipo & Privado \\
\hline Nivel educativo & Carreras técnicas \\
\hline Áreas de formación & Informática y Administración \\
\hline Ubicación & Interior del país, Uruguay \\
\hline Trayectoria & 20 años \\
\hline Aval & Universidad privada \\
\hline Requisitos de ingreso & 1 er año de Educación Media Superior \\
\hline Plan de estudios & 2 años (4 semestres) \\
\hline Carga horaria & 12 horas semanales \\
\hline Docentes & 15 \\
\hline Alumnos & 73 \\
\hline
\end{tabular}




\section{Planteamiento del problema}

Cuando se comenzó con este proyecto de investigación se planteó una entrevista exploratoria con el director de la institución. La problemática emergente se determinó como el estancamiento de la matrícula, situación que el director expresó como preocupante por haberse extendido desde hacía ya aproximadamente diez años. A esto se sumó la falta de análisis de registros de inscripciones y seguimiento de casos por parte de la institución que el propio director manifestó como necesario para la toma de decisiones.

Si bien la problemática fue identificada como tal por el director, éste reconoció que no se ha realizado un estudio o análisis previo de la situación que incluyera diagnóstico de la demanda de capacitación ni de las necesidades del entorno. A los efectos de la investigación y tal como se desprende del apartado siguiente, el disparador quedó planteado en la interrogante: ¿Puede la mejora de la imagen institucional lograr una mayor matriculación de alumnos?

\section{Antecedentes y fundamentación teórica}

En base a esta demanda de trabajo se realizó una búsqueda de antecedentes que pudieran servir de referencia a la investigación. No fue posible encontrar estudios que partieran de un mismo problema emergente. Sin embargo, se accedió a bibliografía que señalaba al marketing como herramienta para procurar nuevos alumnos y retenerlos (Martínez, 2001; Manes, 2000, 2008; Naranjo, 2011).

Es así que se empieza a ahondar en esta temática para comprender qué elementos de la institución pueden estar vinculados a la dificultad presentada a fin de identificar posibles líneas para el plan de mejora organizacional.

A primera vista las referencias hablan del trabajo de diseño y la ejecución de un plan de marketing orientado a mejorar la imagen que usuarios y público tienen de la institución y su oferta educativa (Chaves, 1996). No obstante, se hace necesario reflexionar sobre aspectos internos de la organización que puedan determinar su desarrollo.

Tomando como referencia autores como Gairín (1999) y Santos (2002) que hablan de la idiosincrasia de las organizaciones, su predisposición al cambio y la formación de su identidad, se puede inferir una línea de acción al interior del centro, que complemente el uso del marketing como herramienta para la gestión.

La principal característica de un centro educativo es que se dedica a brindar servicios de formación. Cuando se elige un servicio educativo se está ponderando la calidad de ese servicio brindado, dicha calidad compuesta por dos elementos principales: la forma en que cubre las necesidades intelectuales del usuario (si le interesa, le motiva, le resulta útil emocionalmente y si será una forma potencial de sustento económico y movilidad social) y la medida en que se adapta a las necesidades de formación que requiere el entorno.

Es decir que para poder aplicar técnicas de marketing y transmitir una imagen hacia el exterior primero hay que diagnosticar el estado de la organización e identificar cuáles de sus características pueden ser útiles para la mejora de la calidad educativa. Se buscaron elementos que, asociados, llevaran a este fin. Entre ellos encontramos el desarrollo organizacional y, principalmente, su vinculación con cuatro conceptos: la cultura organizacional, la gestión de procesos, la gestión de conocimiento y el liderazgo. A su vez, estos conceptos permiten influir en cuestiones específicas de la organización como la formación y el desarrollo de comunidades de práctica, la mejora en la coordinación docente, el fortalecimiento del sentimiento de pertenencia y el ejercicio del compromiso, fomentado por el trabajo en equipo, el empoderamiento, la toma de decisiones y la comunicación interna (véase Cuadro 1). 


\section{Cuadro 1. Elementos para lograr la calidad educativa}

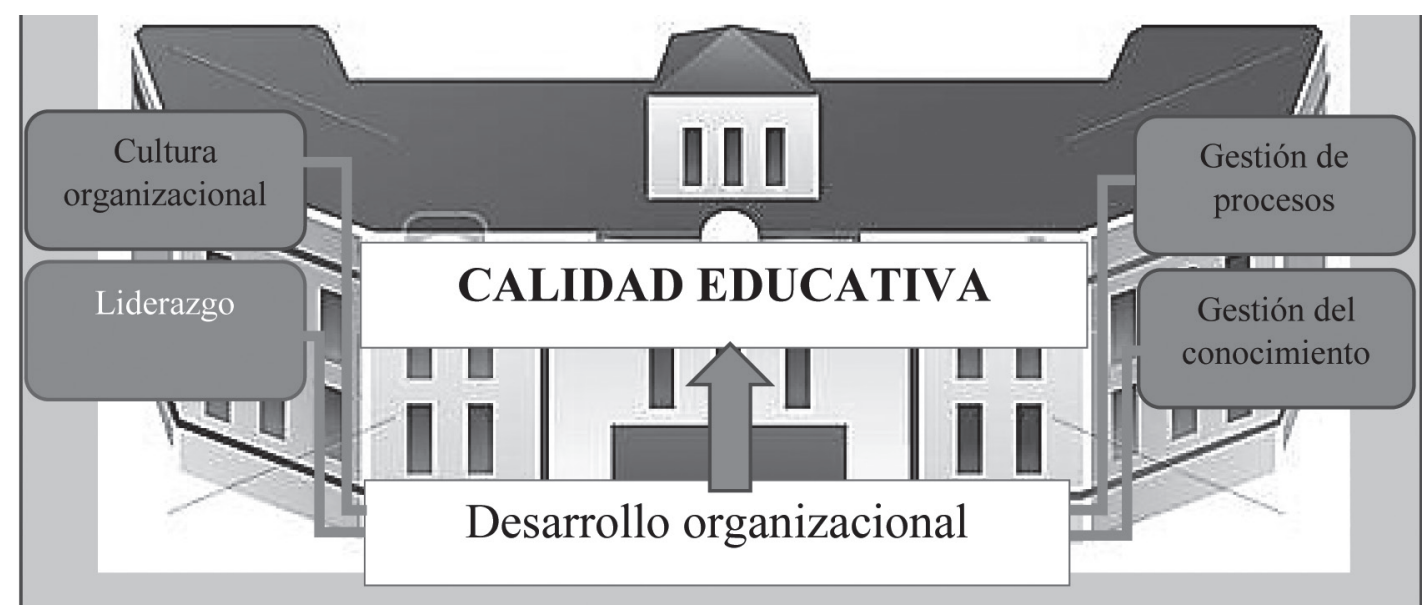

\section{Síntesis de los conceptos teóricos vinculados}

En este apartado se resumen los conceptos identificados y se explica la forma en que se relacionan para dar coherencia al plan de mejora que surge luego de realizada la investigación.

En primer lugar se debe realizar una aproximación a lo que es una institución educativa: una organización compleja donde interactúan distintos actores con un mismo fin, es decir, para procurar brindar o recibir un servicio educativo (Manes, 2000). La institución así definida interactúa con el entorno en una relación de mutua influencia (Gairín, 1999) (Véase Cuadro 2).

\section{Cuadro 2. Concepto de educación educativa}

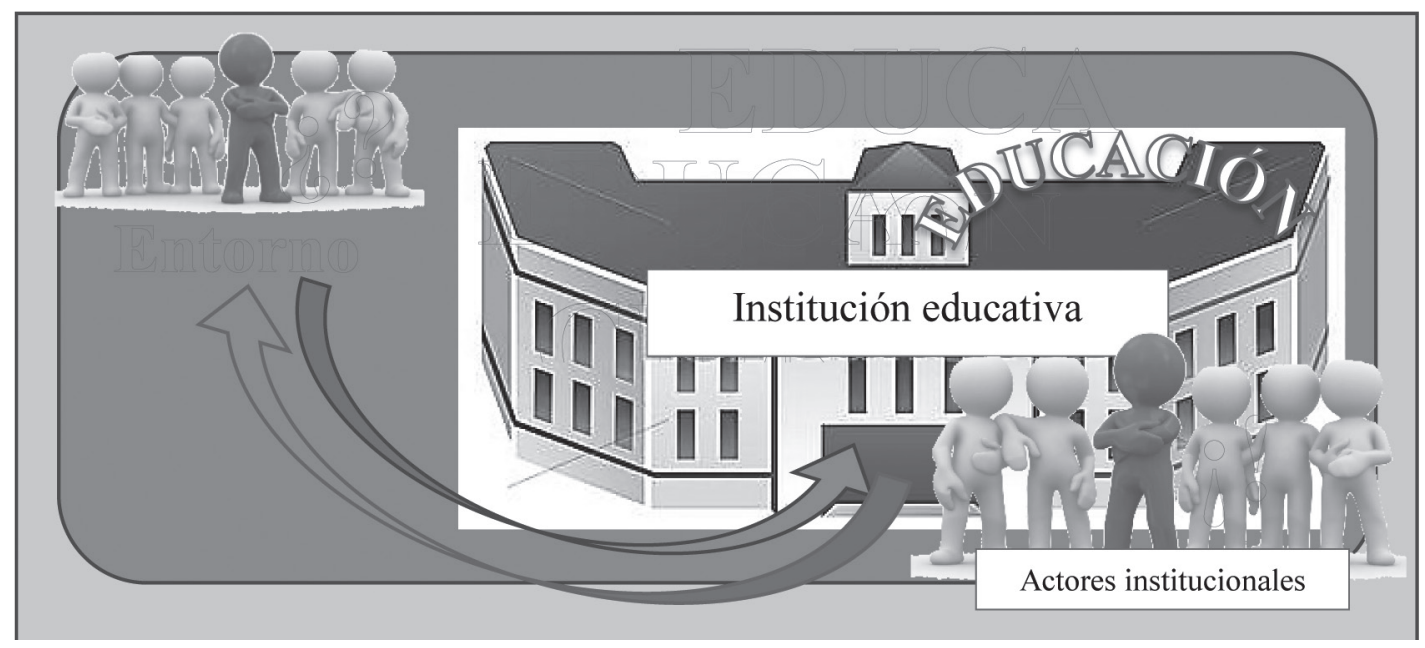

El resultado de esa interacción determina la imagen institucional (véase Cuadro 3), la forma en que el entorno y los usuarios perciben al centro a través de los mensajes que éste transmite y las ideas que se generan en el público (Chaves, 1996). La dinámica de las sociedades, influenciada por los medios de comunicación y el uso de las redes sociales en un momento de hiper-conectividad global hace que la imagen o reputación sea una formulación de frágil equilibrio, por lo que Manes (2008) recomienda realizar mediciones periódicas para monitorear sus transformaciones. 


\section{Cuadro 3. Concepto de imagen institucional}

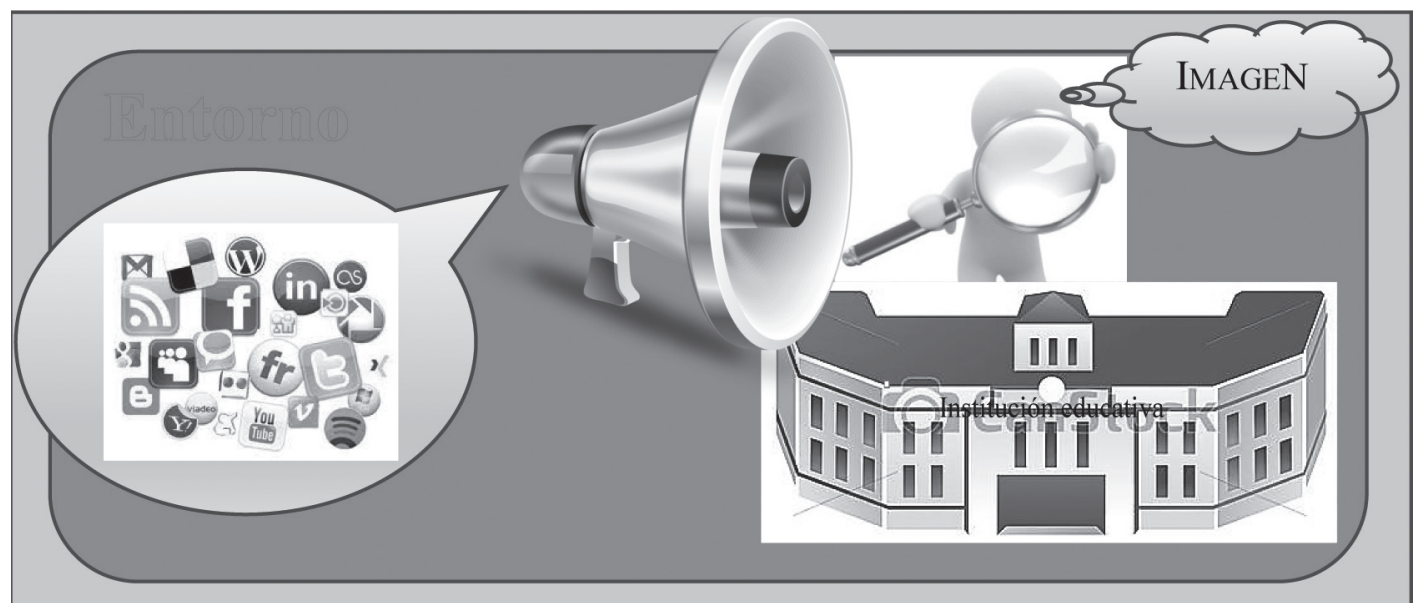

Teniendo en cuenta el concepto de la imagen institucional y sus implicancias respecto de la problemática planteada por el centro objeto del estudio, las ideas-guía del marco teórico se pueden dividir en dos ramas: la intervención en aspectos externos al centro y la promoción de aspectos internos al centro (véase Cuadro 4).

En lo que refiere al trabajo hacia el exterior, el marketing se puede definir como la articulación de aquellos elementos que, entendidos por el conjunto de la organización, logran satisfacer las necesidades de los usuarios. Estos elementos son necesidades, anhelos y demandas de los usuarios, el servicio en sí, el valor y la satisfacción que ese servicio da al usuario, el intercambio, las relaciones y transacciones que se dan para la prestación del servicio y el mercado (Kotler y Armstrong, 2001).

\section{Cuadro 4. Ideas-guías del marco teórico y su articulación}

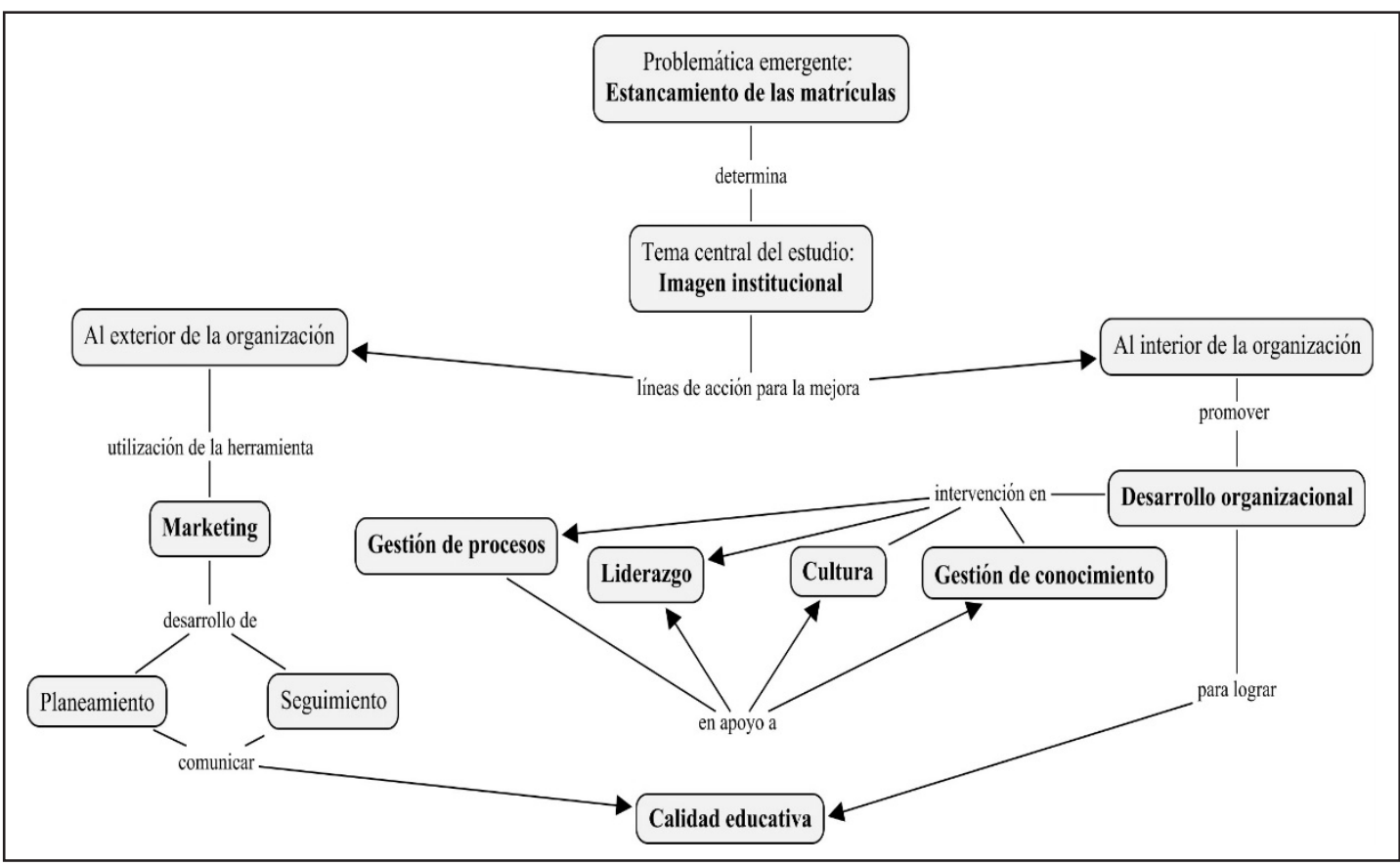


Martínez (2001) agrega a estas ideas las de complejidad y trascendencia que caracterizan, en especial, la aplicación del marketing a los servicios educativos. Se entiende que la complejidad está vinculada al proceso de mejora constante en la educación y a la intangibilidad del servicio brindado, mientras que la trascendencia involucra el logro del bienestar social, motivo por el cual se justifica la aplicación del marketing a la educación (Manes, 2008).

La aplicación de la herramienta marketing al trabajo hacia el exterior del centro debe basarse en el diseño de un plan de comunicación idóneo que utilice los canales adecuados a sus públicos y cuente con mecanismos para medir la retroalimentación (Lambin, 1995). En especial, se considera que la utilización de la estrategia del Manejo de Relaciones con el Cliente (CRM) o la de Manejo de las Experiencias del Cliente (CEM) son las más adecuadas para el logro de una mejora en la imagen institucional, por centrarse en el proceso de acercar valor y satisfacción a los usuarios (Naranjo, 2011).

Para que la aplicación de estas estrategias de marketing sea provechosa, la cultura organizacional deberá enfocarse en el usuario, sus necesidades y su satisfacción, y la calidad del servicio ofrecido debe condecirse con lo comunicado en el plan de manera de transmitir un mensaje basado en la ética (véase Cuadro 5).

\section{Cuadro 5. Idea-guía de Marketing}

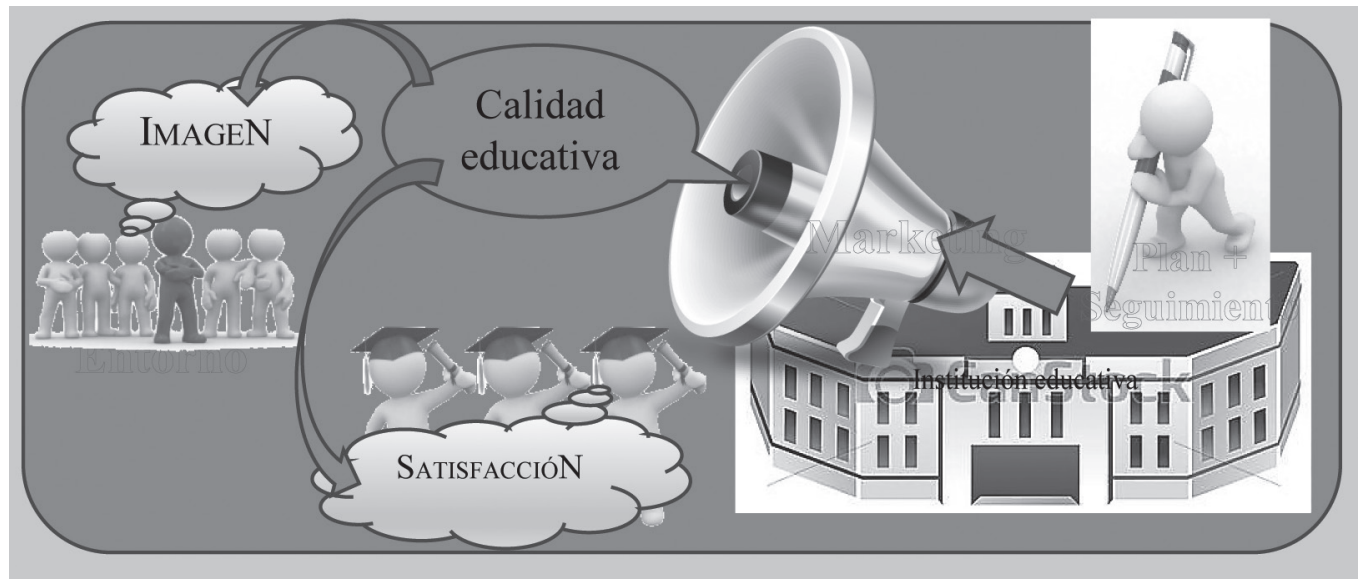

Para que sea posible realizar una aplicación de la herramienta marketing para la gestión de la imagen institucional de manera ética hacia el entorno, es necesario contar con el elemento fundamental de la labor educativa: la calidad. Como señalan diferentes autores, la enseñanza será de calidad en tanto sea efectiva y eficaz (Frigerio, Poggi, Tiramonti y Aguerrondo, 1996), y también en la medida en que se adapte a las necesidades intelectuales de los usuarios y les brinde satisfacción (Parcerisa, 2008; Zapata, 2000) sin descuidar los requerimientos de formación del entorno, es decir del contexto social (Manes, 2008).

Debido a que la calidad de la oferta educativa parte de la combinación de elementos internos a la organización, la línea de acción hacia el interior se basa en la idea-guía desarrollo organizacional. Una institución educativa se puede encontrar en uno de los siguientes estadios de desarrollo: organización texto, organización contexto, organización que aprende u organización que genera conocimiento (Gairín, 1998).

Diagnosticar el estadio en que la institución se encuentra es el puntapié inicial para promover líneas de mejora. La situación más conveniente para alcanzar la calidad educativa la tienen aquellos centros que logran generar conocimiento, y en menor medida, aquellos que se encuentran en situación de aprender a hacer o gestionar los procesos de mejora (Vázquez, 2011). 
Para trabajar en la obtención de la calidad es aconsejable que el desarrollo organizacional se vuelque a cuatro aspectos ya mencionados: la cultura organizacional, la gestión de procesos, la gestión de conocimiento y el liderazgo. La cultura organizacional desempeña un papel fundamental en la motivación de la innovación según sea su postura frente al statu quo y la energía puesta en el trabajo. Asimismo, los elementos de tipo relacional que constituyen la identidad cultural tienen que ver con la orientación al trabajo en equipo, la forma de percibir los logros alcanzados y la evaluación de los efectos de las decisiones en el personal (Robbins, 2004).

La cultura necesaria para lograr el desarrollo organizacional es la "de cambio" (Robbins, 2004), es decir aquella que posee un modelo profesional de gestión (Frigerio et al., 1996) y que se maneja con flexibilidad ante la existencia de subculturas, favoreciendo la promoción de la participación de todos los actores institucionales (Hargreaves, 2005) (véase Cuadro 6).

\section{Cuadro 6. Idea-guía cultura organizacional}

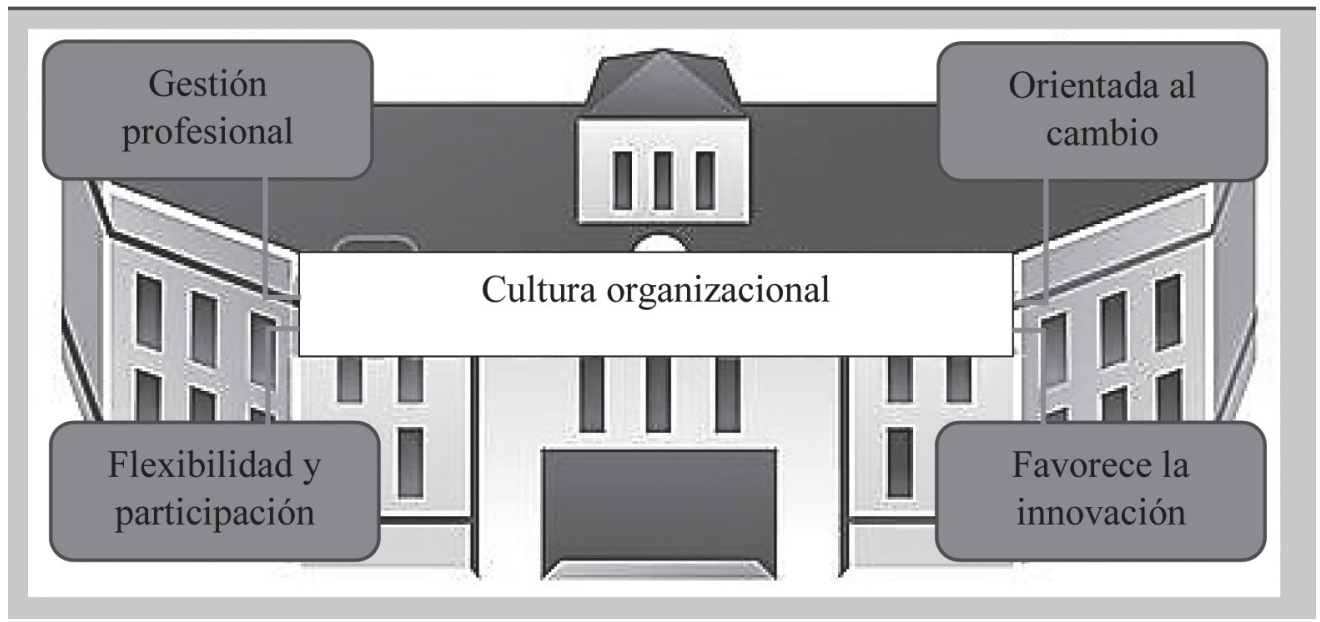

Una cultura organizacional orientada al cambio será el sustrato para lograr procesos de innovación sostenibles, entre ellos los que lleven a la calidad educativa para promover la mejora de la imagen institucional.

Los procesos son la función más importante de la organización, son la serie de acciones diseñadas para que se den ciertos resultados y que esos resultados cumplan con objetivos o metas propuestos (Ewy y Gmitro, 2009). Un proceso es una secuencia de desarrollo de actividades que involucran personas, recursos y materiales para producir resultados planificados y acordes (Pérez, 2005).

A medida que la organización evoluciona, los directivos deben mejorar los procesos que hacen a las personas cumplir con las tareas, teniendo en cuenta los elementos que componen la gestión de procesos (véase Cuadro 7). 


\section{Cuadro 7. Idea-guía gestión de proceso}

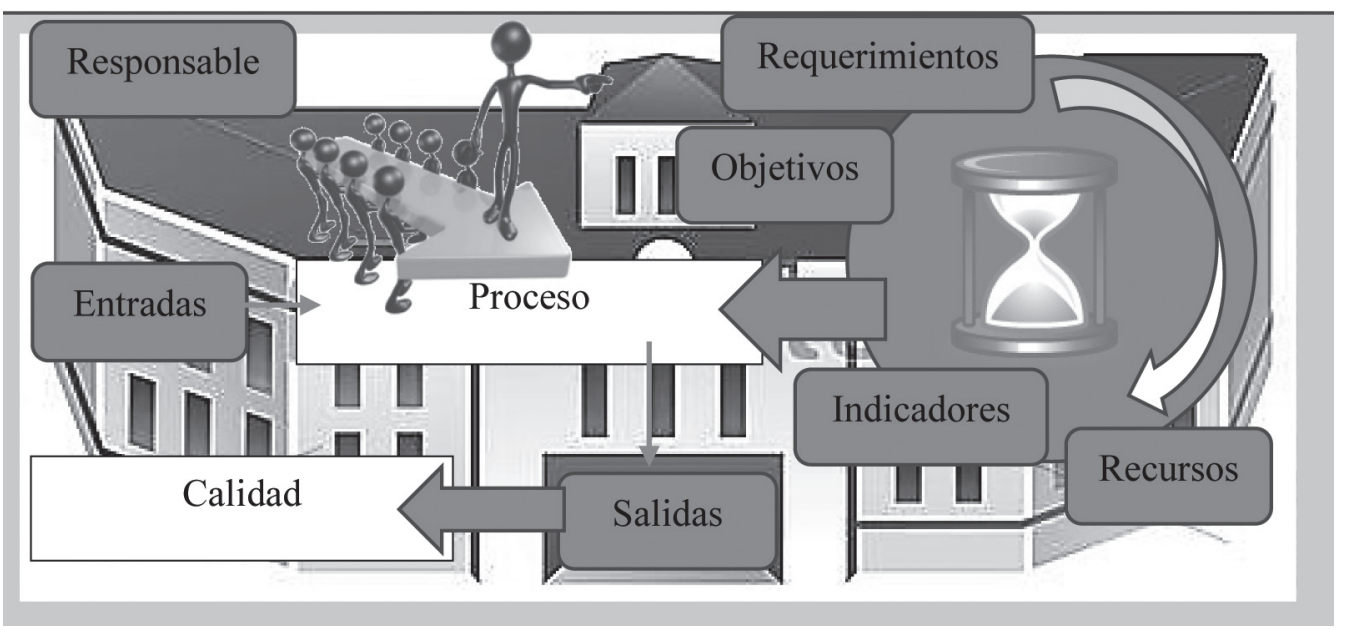

Una vez terminado el ciclo del proceso y con los resultados obtenidos a partir de su evaluación se puede contar con información sobre las dimensiones organizacionales más relevantes, sobre las cuales intervenir para mejorar la calidad educativa (Marchesi y Martín, 1998).

Sin embargo, los directivos y administradores de los centros educativos cuentan con escasa preparación para gestionar procesos organizacionales que lleven a lograr la calidad educativa. Tampoco se logran identificar los procesos críticos de la organización de manera de incorporar los resultados a las dinámicas de cambio organizacional (Vázquez, 2011). Un proceso crítico que se identifica en las instituciones educativas es el de la gestión de conocimiento, otra de las ideas-guía para lograr el desarrollo organizacional y la consecuente calidad educativa (véase Cuadro 8).

\section{Cuadro 8. Idea-guía gestión del conocimiento}

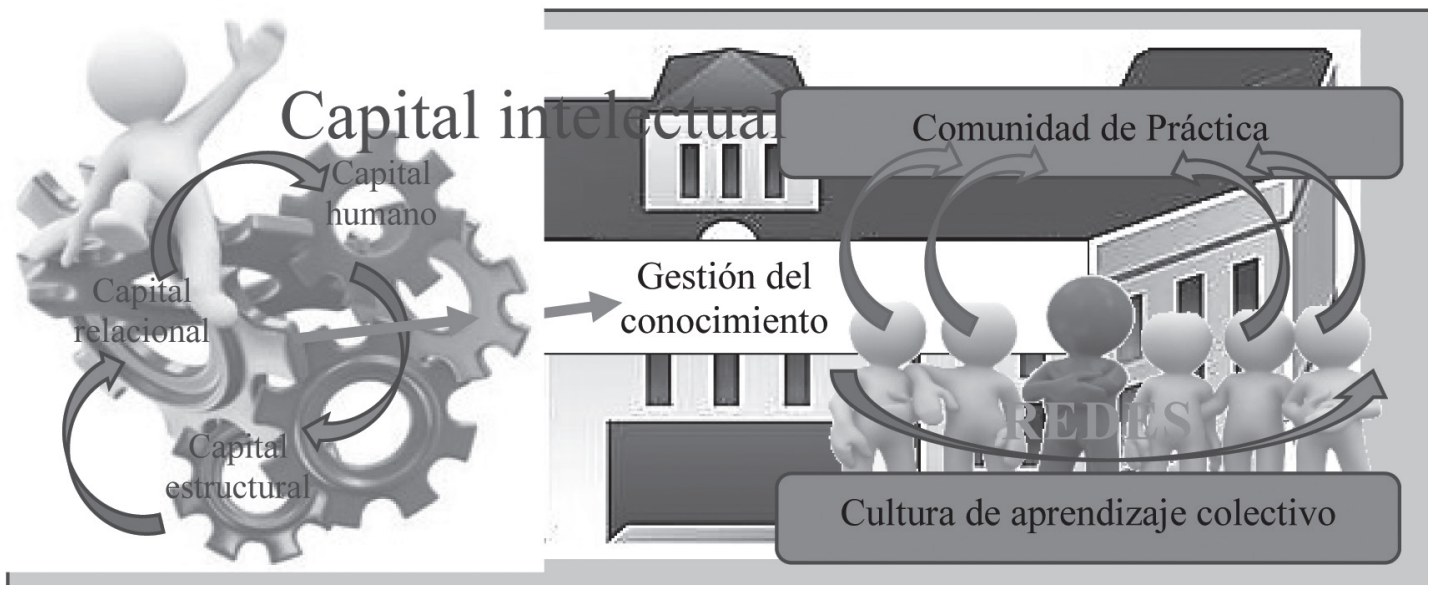


El conocimiento que los individuos poseen debe ser transmitido de modo eficiente, ordenado y constante a fin de ser gestionado para generar una ventaja que consiste en el crecimiento de la institución a nivel organizacional y humano (Rodríguez-Gómez, 2006). Esta gestión debe lograr una cultura de aprendizaje colectivo que se maneje a través de redes virtuales o presenciales (Durán, 2004) para incentivar la formación de comunidades de práctica y potenciar el uso del capital intelectual de la organización mediante la combinación de los elementos que lo forman, el capital humano, el capital relacional y el capital estructural (Rodríguez-Gómez, 2008).

Las ideas hasta ahora desarrolladas se complementan con la de "liderazgo" (véase Cuadro 10). El liderazgo debe partir del equipo de dirección, pero no es necesario que sea ejercido exclusivamente por este grupo. Un equipo de dirección o hasta un director que ejerza el liderazgo podrá promover mediante el empoderamiento para tareas específicas a otros actores institucionales (Covey, 2003, 2005). Esto permitirá obtener otros puntos de vista que aporten a la gestión y favorecerá el compromiso con la institución. Asimismo, deberá fomentar el trabajo y el aprendizaje en equipo (Bernal, 2008), de manera de coordinar a los docentes y generar comunidad de práctica, lo que no se puede alcanzar si no se practica una comunicación interna eficiente y eficaz por su interdependencia con la comunicación externa (Núñez, 2004).

El liderazgo será el motor de la motivación y podrá habilitar al agente de cambio para que su participación afiance los logros y genere más cambios positivos en la cultura organizacional (Kotter, 1997). Es importante aclarar que para el caso de estudio se necesita un liderazgo centrado en el aprendizaje, debido a que el núcleo de este estilo de liderazgo es la calidad de la enseñanza ofrecida (Bolívar, 2010).

\section{Cuadro 9. Idea-guía liderazgo}

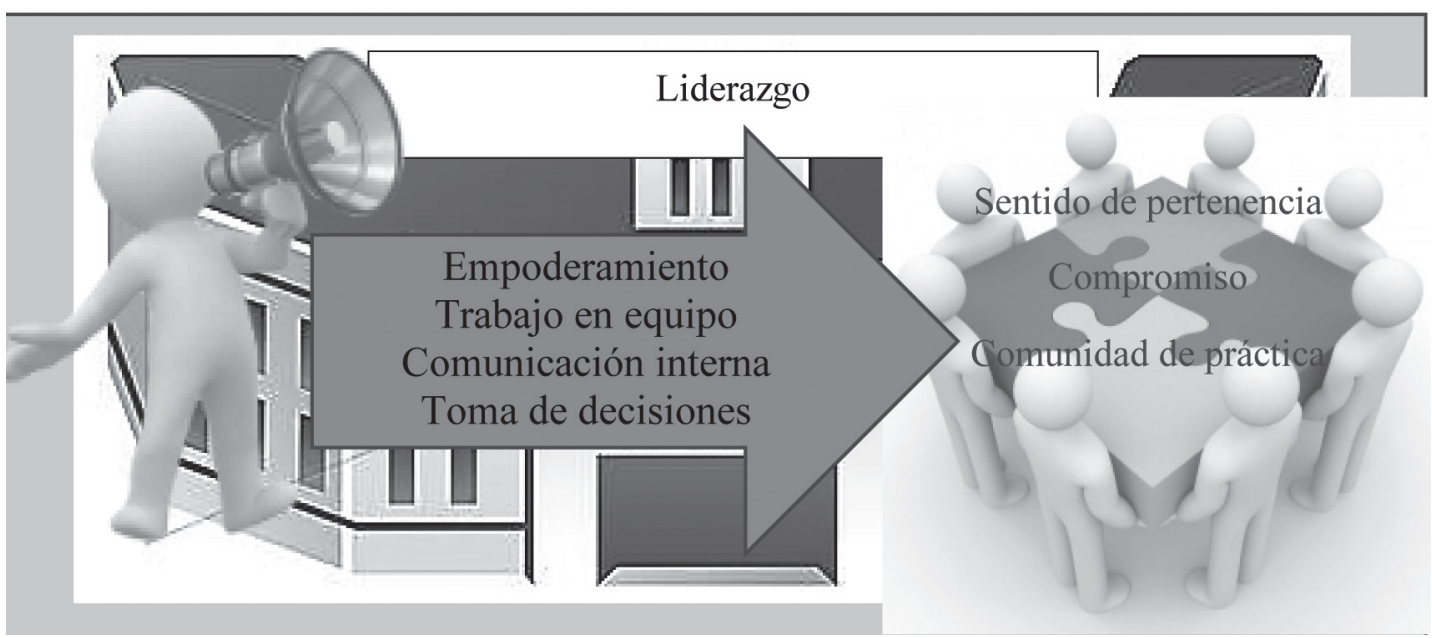

Con estos elementos teóricos como marco de referencia para orientar la investigación se realizó el diseño de la investigación. La interrelación entre los conceptos centrales no solo dio la estructura para determinar la forma en que se abordó el problema sino que también trazó las líneas de acción en el plan de mejora.

\section{Diseño y metodología de la investigación}

Una vez determinada la problemática y definido el marco de referencia sobre el cual apoyar el trabajo, se debió realizar el diseño de la investigación. El diagnóstico comprendió la recolección de datos para realizar el análisis organizacional, para entender las lógicas del funcionamiento del centro y para orientar las decisiones sobre la intervención. 
La metodología utilizada fue el método de casos, herramienta idónea para abarcar el objeto de estudio con instrumentos de carácter cualitativo y cuantitativo, lo que a su vez habilitó la triangulación metodológica optimizando de ese modo la investigación. Las fases que se trazaron se extendieron por espacio de cuatro meses, entre mayo y agosto de 2012 (véase Tabla B).

\section{Tabla B. Fases del estudio diagnóstico}

\begin{tabular}{|c|c|c|c|c|c|}
\hline \multicolumn{2}{|c|}{ Fases del Diagnóstico } & \multirow{2}{*}{ 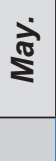 } & \multirow{2}{*}{$\stackrel{5}{5}$} & \multirow{2}{*}{ 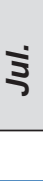 } & \multirow{2}{*}{ த் } \\
\hline \multirow{7}{*}{$\begin{array}{l}\text { Fase 1: Identificación de la } \\
\text { demanda }\end{array}$} & Aproximación al centro & & & & \\
\hline & Realización de entrevista exploratoria & & & & \\
\hline & Búsqueda de antecedentes & & & & \\
\hline & Identificación de actores/sectores implicados & & & & \\
\hline & Matriz & & & & \\
\hline & Recopilación documental & & & & \\
\hline & Modelo de análisis & & & & \\
\hline \multirow{6}{*}{$\begin{array}{c}\text { Fase 2: Comprensión del } \\
\text { problema }\end{array}$} & Antecedentes & & & & \\
\hline & Técnicas complementarias & & & & \\
\hline & Encuestas en línea & & & & \\
\hline & Entrevistas semi-estructuradas & & & & \\
\hline & Observación & & & & \\
\hline & Aplicación de la técnica del iceberg & & & & \\
\hline \multirow{4}{*}{$\begin{array}{c}\text { Fase 3: Reconocimiento de } \\
\text { necesidades }\end{array}$} & Identificación de fortalezas y debilidades & & & & \\
\hline & Definición de prioridades & & & & \\
\hline & Dimensiones involucradas en la mejora & & & & \\
\hline & Personas implicadas (grupo impulsor) & & & & \\
\hline \multirow{2}{*}{$\begin{array}{l}\text { Fase 4: Acuerdos con la } \\
\text { organización }\end{array}$} & Sistematización de la información & & & & \\
\hline & Redacción del informe de avance & & & & \\
\hline
\end{tabular}

La primera fase implicó un acercamiento primario al centro para luego realizar la entrevista exploratoria al director. En este encuentro se identificó la demanda o problema a investigar: el estancamiento de las matrículas. Durante el transcurso de esta fase también se realizó una recopilación documental en el centro que evidenció la falta de estadísticas de inscripciones o desempeño, estudios comparativos, sistematización de la información o análisis del impacto del uso de medios de comunicación para el contacto del centro con el entorno.

Se pudo acceder a información vía correo electrónico mediante preguntas directas al coordinador y a la secretaria y de esa forma se completó un panorama de la situación del centro respecto del problema planteado. Complementando esta fase se creó un modelo de análisis. En este modelo se vincula la problemática identificada, las dimensiones de la organización involucradas y los sectores de la institución relacionados con una serie de factores causales que podrían estar influyendo en el estancamiento de la matrícula (véase Cuadro 10). 


\section{Cuadro 10. Modelo de análisis para el diagnóstico}

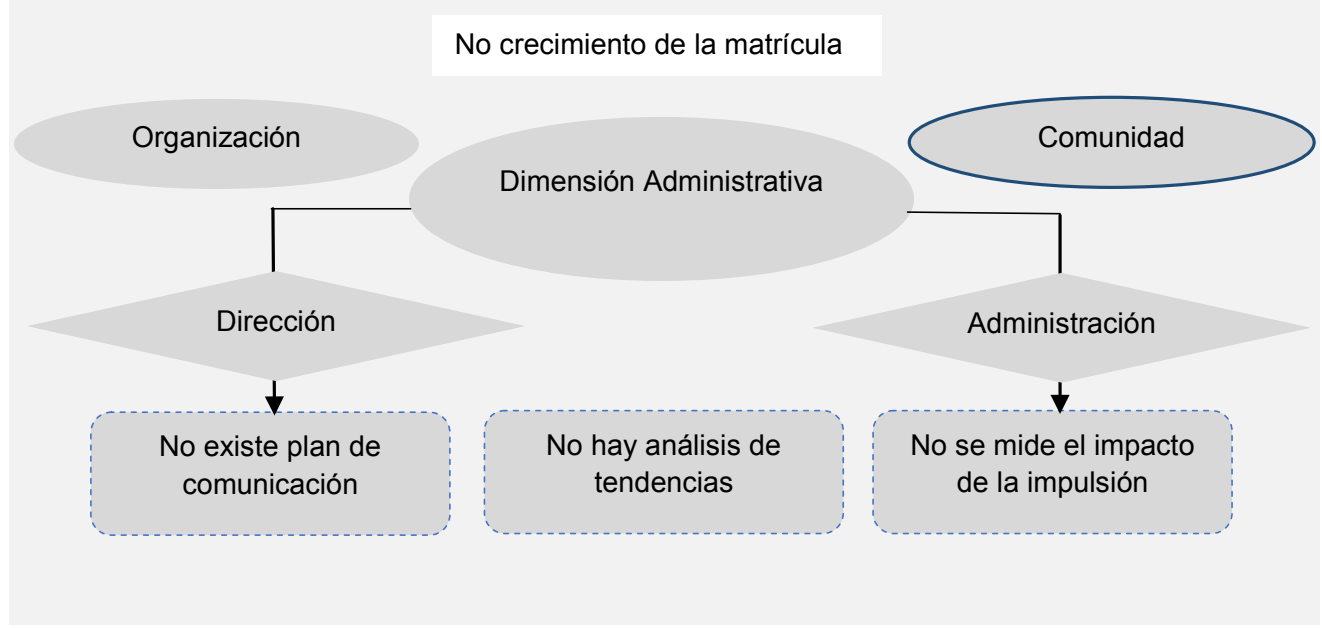

En base al diseño de la matriz se definieron las técnicas más apropiadas para realizar la recolección de datos complementaria, técnicas que se desarrollaron durante la segunda fase del diagnóstico. Se plantearon, testearon y aplicaron una entrevista semi-estructurada, un cuestionario auto-administrado en línea, observación de participación pasiva y análisis documental (véase Tabla C).

Tabla C. Detalle de instrumentos utilizados en la segunda fase

\begin{tabular}{|l|l|c|}
\hline \multicolumn{1}{|c|}{ Instrumento } & \multicolumn{1}{c|}{ Informante } & Aplicación \\
\hline Entrevistas semi-estructuradas & $\begin{array}{l}\text { Directores de ambos centros } \\
\text { Docente de ambos centros } \\
\text { Secretarias de ambos centros }\end{array}$ & Julio y agosto \\
\hline Encuesta auto-administrada en línea & $\begin{array}{l}\text { Alumnos actuales } \\
\text { Alumnos desertores } \\
\text { Egresados }\end{array}$ & Julio y agosto \\
\hline Observación pasiva & Instalaciones del centro & Agosto \\
\hline Análisis de documentos & Institución y Web & Julio y agosto \\
\hline
\end{tabular}

Los datos recogidos fueron analizados para depurar la información relevante a los efectos de la investigación. Con este insumo se pudo emplear la técnica del iceberg para determinar las lógicas de la cultura organizacional. Los resultados de la aplicación de esta técnica permitieron identificar aspectos de las dinámicas institucionales relacionados con el problema tanto en el nivel visible como en las prioridades institucionales y los elementos subyacentes de la cultura.

Ahondando en la aproximación diagnóstica y como parte de la tercera fase se confeccionó una matriz FODA (Fortalezas, Oportunidades, Debilidades y Amenazas) que hizo posible identificar los aspectos prioritarios y complementarios de manera de tener una perspectiva para el diseño del plan de mejora. Se tuvieron en cuenta también las dimensiones que debían estar involucradas en la mejora y se vislumbraron las personas implicadas que podrían formar parte del grupo impulsor del plan de mejora, es decir, que interviniesen en la fase de diseño del mismo. 
Para finalizar, durante la cuarta y última fase del diagnóstico se sistematizó la información y se redactó un informe con las líneas de negociación a sugerir al centro para el esbozo del plan de mejora.

\section{Análisis de datos}

Los datos recabados mediante la aplicación de las diversas técnicas permitieron identificar elementos recurrentes que delinearon ejes temáticos asociados a la problemática y factores causales complementarios. Las categorías de análisis se refirieron a la imagen del centro, la comunicación interna, la situación de los docentes y los fundamentos de los usuarios para optar por el centro.

Respecto de la imagen del centro se detectó una discrepancia entre lo que la institución quiere transmitir, lo que se percibe en el entorno y la visión que de él tienen los usuarios y sus familias. Por un lado el centro desea transmitir un determinado nivel de propuesta educativa y trayectoria, independiente de la Universidad que la avala. Sin embargo, para los usuarios no existe diferencia entre el centro y la Universidad. Pese a esto el entorno parece darle una calificación menor a la institución, lo que se contradice en esencia con otra visión donde se asocia al centro con precios elevados por los servicios a raíz de su vínculo con la Universidad, a pesar de la publicidad existente sobre sistemas de becas o convenios celebrados con empresas.

Entre las opiniones recabadas en las encuestas la imagen del centro es positiva ya que un $100 \%$ de las respuestas admite que recomendaría las carreras a otros interesados, esgrimiendo como motivo principal la salida laboral existente (más del $60 \%$ de los encuestados).

Esta información surge del análisis de datos extraídos de las entrevistas semi-estructuradas, de cuestionarios contestados vía correo electrónico y de las encuestas a alumnos egresados. También se tomó como fuente de información la página Web de la Red de centros, la página institucional en la red social Facebook ${ }^{\circledR}$, carteles existentes en el centro, folletos y anuncios en prensa escrita.

En cuanto a la comunicación interna los problemas detectados pueden influir indirectamente en la problemática y afectar la imagen institucional. Esta categoría se evaluó desde dos perspectivas. Por un lado, se observó lo relativo al liderazgo y por otro, los aspectos referidos a la coordinación docente. El liderazgo, como factor dinamizante, da forma a la cultura organizacional y a los procesos de cambio.

De las entrevistas semi-estructuradas surgen comentarios sobre el manejo de la comunicación por parte de la dirección, como una cuestión ligada a la toma de decisiones. Se expresa que la dirección puede tomar decisiones pero que el mecanismo para darlas a conocer no es eficaz, demorándose en algunos casos o permaneciendo, en parte, vedado a otros actores institucionales. Esto afecta también el clima institucional, que repercute en la coordinación académica y, por ende, en la calidad del servicio brindado. La actividad docente no sigue pautas de funcionamiento claras y la práctica docente se ve afectada, tal como se desprende de las entrevistas a actores clave de la organización. La forma de coordinar es errática a causa del estilo de liderazgo que podríamos llamar de "laissez faire, laissez passer"; los docentes no conocen la planificación anual del centro ni la periodicidad de los encuentros de coordinación, que varían de semestre a semestre. Asimismo, no están interiorizados sobre aspectos del funcionamiento del dictado de cursos o la forma de comunicar las decisiones académicas que debe tener en cuenta la administración. Sin embargo, la apreciación de algunos de los entrevistados es que el director está en el centro en el momento de mayor actividad, monitoreando el funcionamiento global de la institución, lo que lo llevaría a tener un conocimiento superficial de las actividades cotidianas. La presencia del director en el momento del dictado de los cursos puede contribuir a la formación de una imagen positiva en los usuarios. 
A pesar de la visible carencia en la comunicación con los docentes, que se desprende de la falta de carteleras, sala de profesores y de la escasa coordinación entre materias, la comunicación con los usuarios parece ser buena a juzgar por la opinión de los egresados quienes, en un $88 \%$ de los casos, responden que mantienen comunicación con el centro por diferentes motivos, y un $95 \%$ de los estudiantes actuales dice haber recibido la carta inicial que explica el funcionamiento de la institución y el régimen de las carreras.

En lo que respecta a la categoría de análisis referida a los docentes, también se aprecian dualidades en la visión de los actores institucionales. Las contradicciones pasan por ver a los docentes como una fortaleza del centro pero, a su vez, se habla de problemas en cuanto a la responsabilidad y la dedicación de los profesores, que se evidencian en las entrevistas. Esto impacta en el sentido de pertenencia de los docentes y en su compromiso con la institución.

Otro aspecto evaluado es el nivel de aprendizaje. Los alumnos consideran en un $74 \%$ que el nivel es bueno, aunque opinan que la bibliografía es buena pero muy estructurada, según lo obtenido en la recopilación documental de encuestas a alumnos realizadas por una consultora externa. En esas mismas encuestas surgen quejas sobre el dictado de las clases, el rol del docente en la clase y la demora en la entrega de resultados de pruebas o exámenes por parte de los profesores. Sin embargo, las opiniones vertidas en las encuestas administradas para esta investigación dan cuenta de la imagen positiva sobre los docentes. Por la divergencia de opiniones esta categoría resulta relevante para el plan de mejora.

Para analizar la categoría "motivos de opción por el centro" se vinculó la opinión de actores entrevistados con la información de las encuestas a estudiantes y egresados. En este punto también se encuentra una divergencia relevante debido a que los directivos piensan que las herramientas con las que el centro se da a conocer son, en primer lugar, las publicaciones en prensa escrita y las charlas en liceos; en segundo lugar los anuncios vía correo electrónico y en televisión y por último el uso de redes sociales, el portal Web y el "boca a boca". Entre los estudiantes y egresados, las respuestas pusieron en primer lugar a la folletería y el "boca a boca", luego Internet y prensa escrita y por último la televisión.

Otros de los aspectos a considerar en este punto son la persona del centro con la que se contactó en primera instancia y la impresión inicial al llegar a la institución. En todas las categorías de usuarios el primer contacto fue de más del $70 \%$ con la secretaria, considerando "excelente" el trato dispensado y las respuestas a las inquietudes en un $60 \%$.

Incentiva también la elección por el centro la cercanía al domicilio, luego el interés por la formación específica y por último la salida laboral. Estos datos, contrastados con la opinión recabada en las entrevistas semi-estructuradas demuestran una discrepancia, debido a que desde la organización se cree que la motivación para elegir el centro se basa en la certificación de la Universidad y la salida laboral como causas principales. Estas diferencias entre lo que cree la organización y lo que piensan los usuarios fue otro de los puntos a incluir en el plan de mejora.

\section{Resultados obtenidos}

Una vez sistematizados los datos y procesada la información se trabajó con la técnica del iceberg para determinar las necesidades de la organización (véase Cuadro 12). Estas necesidades se identifican a partir de la profundización en el análisis de la cultura institucional.

En el nivel de lo visible se sitúa el convenio con la Universidad para el aval de los certificados, la excelencia docente por contar con profesionales del área, la ubicación relativa del centro en el contexto, la dedicación del director que parece estar siempre presente en el horario de funcionamiento de los cursos, y el trato personalizado y humano favorecido por la poca cantidad de alumnos. 


\section{Cuadro 11. Análisis de la cultura institucional}

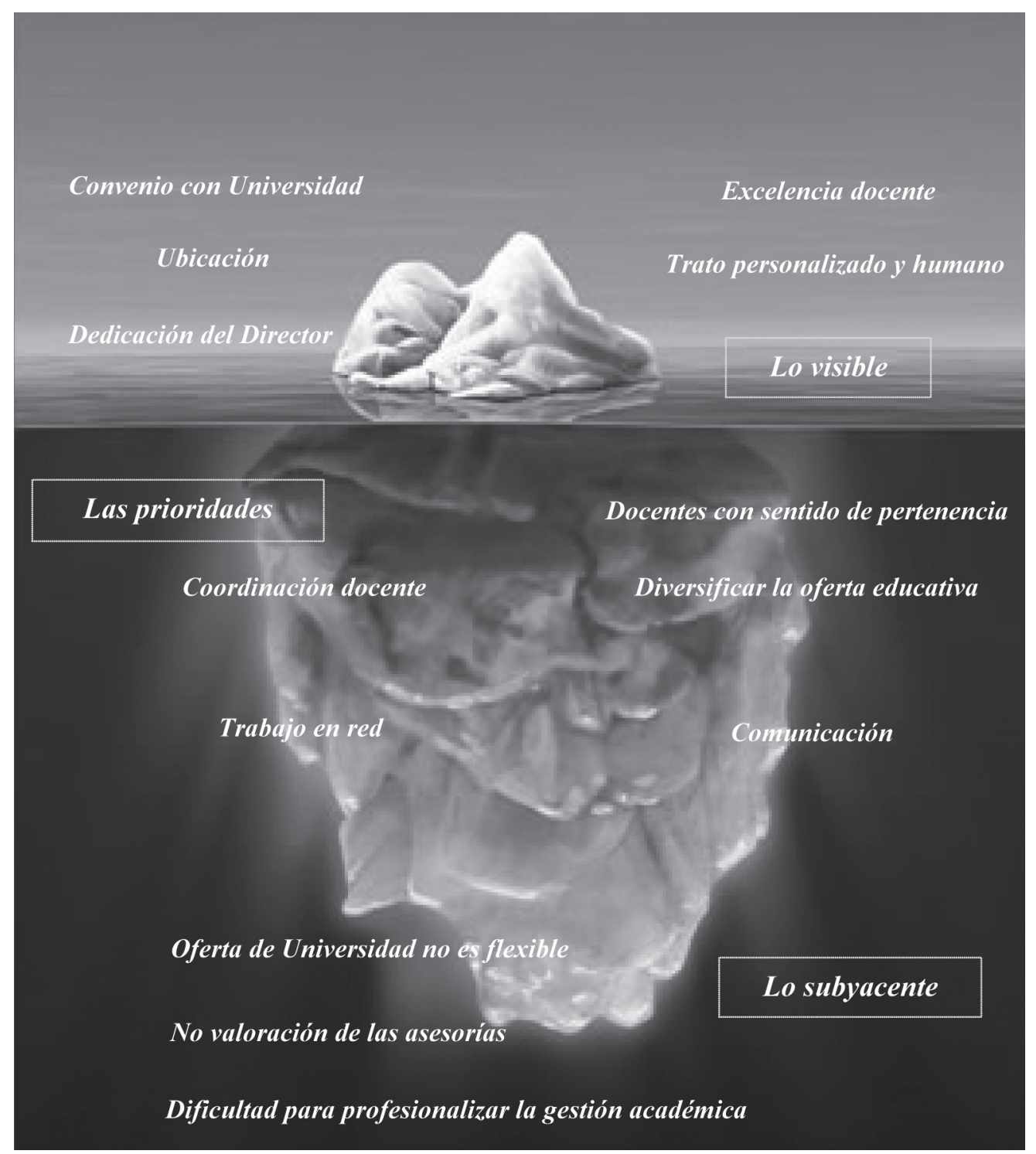

Siguiendo con el análisis, las prioridades se basan en lograr coordinación docente, debido a que los profesores no se conocen entre sí ni planifican en conjunto. Para lograr coordinación se necesita comunicación y trabajo en red, tanto entre los docentes del centro como con otros de la Red de centros y de la Universidad. Esto favorecería la creación de sentido de pertenencia por parte de los docentes y mejoraría el compromiso con la tarea.

Por último y como forma de aumentar las matriculaciones a corto plazo se podría diversificar la oferta educativa con nuevas carreras.

En lo más profundo de la cultura se encuentran elementos subyacentes que condicionan el desarrollo: el sentimiento de que la oferta de cursos de la Universidad no es flexible, la dificultad para profesionalizar la gestión académica que debilita la coordinación docente, y las asesorías externas que no son tenidas en cuenta como insumo para el proceso de mejora organizacional. 
Asimismo, con los datos recolectados se pudo realizar una matriz FODA (véase Cuadro 12), donde se identificaron fortalezas y oportunidades de la organización, así como también debilidades y amenazas. Con los datos de la matriz se obtuvieron varias combinaciones, por ejemplo que la ubicación geográfica es estratégica debido a la combinación de la poca competencia con la necesidad de formación a bajo costo.

\section{Cuadro 12. Matriz FODA}

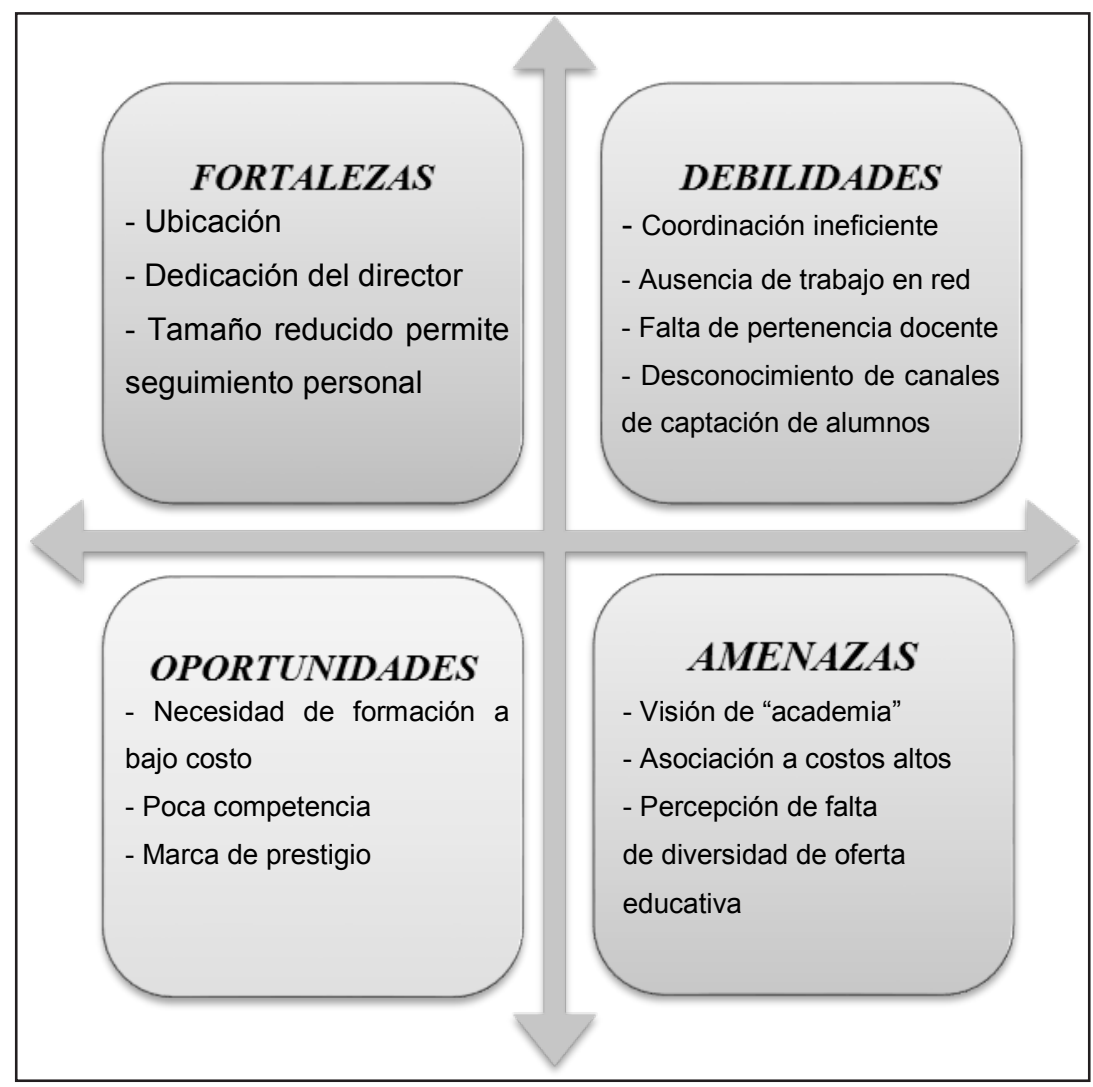

Asimismo la falta de estudios sobre el mercado y la forma en que se perciben los canales de comunicación como idóneos son la causa de que las campañas de captación de alumnos no estén diseñadas con un proceso de seguimiento, corrección y análisis de impacto. Por otro lado, el tamaño reducido del centro en cuanto a matrícula y su ubicación geográfica pueden estar relacionados con la visión de "academia" que de ese centro parece tener el entorno. La marca de prestigio que brinda la asociación con la Universidad no es explotada para revertir esta visión del entorno y tampoco se apoya en la formación de redes entre docentes cuyo trabajo se percibe descoordinado, lo que sumado a la falta de sentido de pertenencia entre los profesores funciona como un elemento negativo en la visión general del centro.

Los aspectos más relevantes para incluir en el plan de mejora surgen de estos análisis. Dichos aspectos delinean la propuesta del plan de mejora que se plasmó como último componente del informe de avance, de manera de anticipar a la institución las líneas de acción sobre las cuales se trabajaría en la etapa siguiente al diagnóstico.

Los resultados del diagnóstico fueron los insumos necesarios para negociar con la institución la forma y las líneas a utilizarse para desarrollar el plan de mejora organizacional. El diseño del plan de mejora se planteó en tres fases (véase Tabla $D$ ) en las que se trabajó con los representantes del centro entre setiembre y diciembre de 2012. 
Tabla D. Fases de desarrollo del plan de mejora organizacional

\begin{tabular}{|c|c|}
\hline \multicolumn{2}{|r|}{ Plan de Mejora Organizacional } \\
\hline FASE 1 & - Entrega del Informe de Avance al centro \\
\hline Setiembre - octubre & $\begin{array}{l}\text { - Negociación de actores institucionales a participar y cronograma de } \\
\text { trabajo en equipo }\end{array}$ \\
\hline \multirow{7}{*}{$\begin{array}{l}\text { FASE } 2 \\
\text { Octubre - noviembre }\end{array}$} & - Desarrollo de reuniones y definición de: \\
\hline & ○ Objetivos (general y específicos) \\
\hline & ○ Logros proyectados (metas) \\
\hline & ○ Líneas de actividad \\
\hline & ○ Cronograma de aplicación del plan \\
\hline & - Elaboración de los instrumentos de seguimiento \\
\hline & - Proyección de sustentabilidad del plan \\
\hline FASE 3 & - Entrega del Plan de Mejora al centro \\
\hline Diciembre & - Evaluación del trabajo \\
\hline
\end{tabular}

Debido a que la problemática planteada por el centro se relacionaba con la imagen institucional y que del diagnóstico surge la falta de procesos adecuados en la organización para manejar los aspectos relacionados con este concepto, se incluyó en el plan de mejora el trabajo con la herramienta marketing. Dicha inclusión se fundamenta en que se constató, por parte del centro, la falta de planificación del uso de los canales de comunicación internos y externos así como la carencia de estrategias sostenidas y sistemáticas de captación de alumnos. También se percibió que los esfuerzos por relacionarse con la comunidad no han influido positivamente en la imagen del centro por lo que no se ha generado un aumento de las inscripciones.

El grupo de trabajo que incluyó a tres representantes de la institución -director, secretaria y coordinador académico- trabajó sobre dos ideas fundamentales. La primera fue el rol de los docentes como instrumento para el cambio, y la segunda la utilización de los vínculos con la comunidad como herramientas para gestionar la imagen.

Los detalles de la elaboración del plan se muestran a continuación (véase Tabla E). 


\section{Tabla E. Detalles del plan de mejora organizacional}

\begin{tabular}{|c|c|c|c|c|c|}
\hline \multicolumn{6}{|c|}{ Detalle del Plan de Mejora Organizacional } \\
\hline \multirow{6}{*}{ 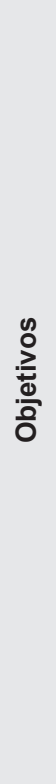 } & 胥 & $\begin{array}{l}\text { Lograr un aumento de la matrícula } \\
\text { mediante una mejora en la imagen } \\
\text { institucional del centro }\end{array}$ & \multirow{6}{*}{$\stackrel{\substack{\pi \\
\stackrel{0}{0}}}{\Sigma}$} & \multicolumn{2}{|c|}{$\begin{array}{l}\text { Aumentar un } 15 \% \text { el número de inscriptos en } \\
\text { el centro en el plazo de un año }\end{array}$} \\
\hline & \multirow{5}{*}{ 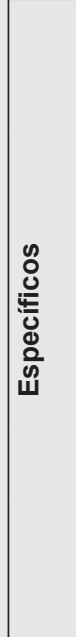 } & $\begin{array}{l}\text { 1. Fomentar el sentido de pertenencia } \\
\text { y el compromiso docente mediante la } \\
\text { mejora de la coordinación entre los } \\
\text { actores institucionales }\end{array}$ & & \multicolumn{2}{|c|}{$\begin{array}{l}80 \% \text { de los docentes concurriendo a las tres } \\
\text { reuniones de coordinación propuestas por la } \\
\text { dirección en cada semestre durante el año }\end{array}$} \\
\hline & & $\begin{array}{l}\text { 2. Crear un plan de colaboración } \\
\text { con otras instituciones de la zona/ } \\
\text { departamento }\end{array}$ & & \multicolumn{2}{|c|}{$\begin{array}{l}\text { Vinculación con al menos dos instituciones } \\
\text { de la zona en el período de un año, de } \\
\text { manera de crear redes en colaboración que } \\
\text { favorezcan el conocimiento del centro en la } \\
\text { comunidad }\end{array}$} \\
\hline & & $\begin{array}{l}\text { 3. Mejorar la práctica docente en el } \\
\text { aula mediante una mayor coordinación } \\
\text { del profesorado }\end{array}$ & & \multicolumn{2}{|c|}{$\begin{array}{l}80 \% \text { de los docentes compartiendo sus } \\
\text { prácticas en la plataforma virtual de la } \\
\text { institución en cada semestre durante un año }\end{array}$} \\
\hline & & $\begin{array}{l}\text { 4. Promover el desarrollo profesional } \\
\text { en ventas del personal administrativo }\end{array}$ & & \multicolumn{2}{|c|}{$\begin{array}{l}\text { Tres sesiones formativas en atención al } \\
\text { cliente y ventas en un período de un mes }\end{array}$} \\
\hline & & $\begin{array}{l}\text { 5. Mejorar los sistemas de } \\
\text { comunicación externa de la institución } \\
\text { hacia usuarios actuales y potenciales }\end{array}$ & & \multicolumn{2}{|c|}{$\begin{array}{l}\text { Un plan de comunicación y un instrumento } \\
\text { de seguimiento de la aplicación del plan, } \\
\text { disponibles al finalizar el primer año de } \\
\text { intervención }\end{array}$} \\
\hline \multirow{7}{*}{ 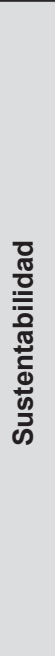 } & \multirow{5}{*}{ 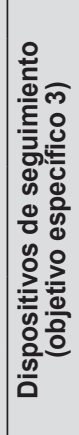 } & Técnica propuesta & Ap & cación & Indicadores de avance \\
\hline & & Planilla de monitoreo & $\begin{array}{l}\text { Dura } \\
\text { desa } \\
\text { plan }\end{array}$ & $\begin{array}{l}\text { te el } \\
\text { ollo del }\end{array}$ & $\begin{array}{l}\text { Se informa al grupo de trabajo el } \\
\text { avance mensual por actividad }\end{array}$ \\
\hline & & Informe de utilización de la plataforma & $\begin{array}{l}\text { Sem } \\
\text { y } 49\end{array}$ & าа 28 & $\begin{array}{l}\text { Un reporte mensual de } \\
\text { participación de los docentes en la } \\
\text { plataforma }\end{array}$ \\
\hline & & Encuesta a alumnos & $\begin{array}{l}\text { Sem } \\
\text { y } 45\end{array}$ & 26 & $\begin{array}{l}70 \% \text { de las encuestas contestadas } \\
\text { resultan positivas }\end{array}$ \\
\hline & & Escala de opinión a docentes & $\begin{array}{l}\text { Sem } \\
\text { y } 44\end{array}$ & า 25 & $\begin{array}{l}70 \% \text { de los docentes se muestran } \\
\text { favorables }\end{array}$ \\
\hline & \multirow[b]{2}{*}{ 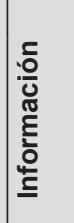 } & Socialización de la información & & usión & Destinatarios \\
\hline & & $\begin{array}{l}\text { Difusión de comunicados internos } \\
\text { mediante el uso de correo electrónico } \\
\text { y plataforma }\end{array}$ & $\begin{array}{l}\text { Tres } \\
\text { por s }\end{array}$ & $\begin{array}{l}\text { casiones } \\
\text { mestre }\end{array}$ & Docentes y personal administrativo \\
\hline \multicolumn{6}{|c|}{ Supuestos de realización: } \\
\hline $\begin{array}{l}\bullet \\
. \\
-\end{array}$ & $\begin{array}{l}\text { Los c } \\
\text { Los c } \\
\text { El pla }\end{array}$ & $\begin{array}{l}\text { irectores permanecen en la organización } \\
\text { ocentes son motivados en la formación c } \\
\text { n de comunicación es monitoreado y eve }\end{array}$ & le una & la vez q & $\begin{array}{l}\text { de práctica } \\
\text { e se corrigen los principales desvíos }\end{array}$ \\
\hline \multirow{4}{*}{ o̊ } & \multicolumn{5}{|c|}{ Presupuesto } \\
\hline & \multicolumn{5}{|c|}{ Modelos de instrumentos de seguimiento } \\
\hline & \multicolumn{5}{|c|}{ Diagrama Gantt } \\
\hline & \multicolumn{5}{|c|}{ Matriz RASCI (Responsable, Aprobador, Soporte, Consultado, Informado) } \\
\hline
\end{tabular}




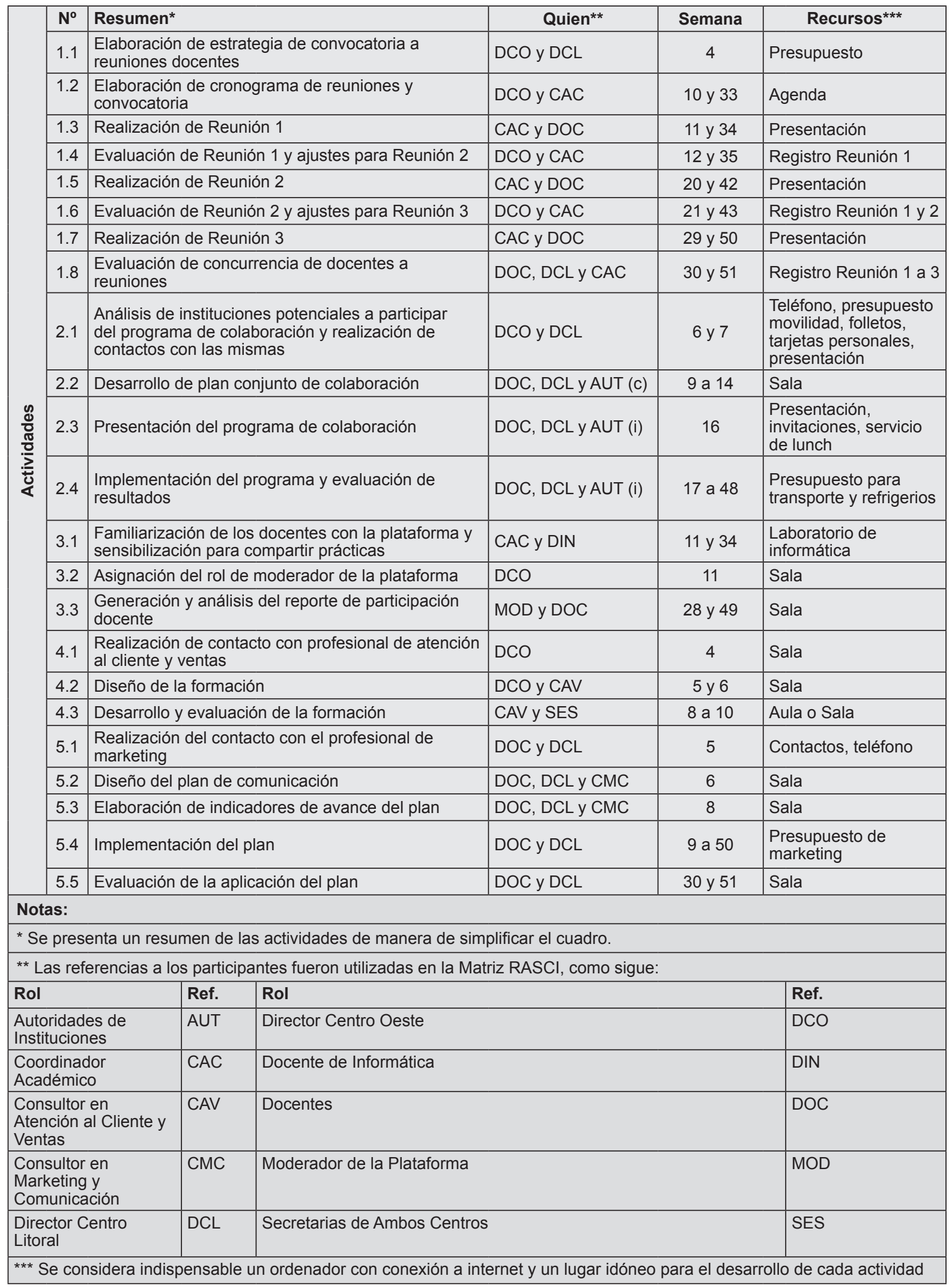




\section{Discusión de resultados}

Durante la etapa de diagnóstico se identifica un problema de estancamiento de matrículas persistente en el centro y que se asocia a la imagen institucional, en base al encuadre teórico resultante de la consulta de bibliografía especializada.

Los resultados de la investigación trazan dos líneas claras de trabajo; primero, el trabajo al interior del centro, donde mediante la actuación sobre elementos intrínsecos de la organización tales como la cultura y el desarrollo organizacional se pueda lograr la calidad educativa, vista como la adecuación de la oferta educativa del centro a la demanda o a la necesidad de formación del entorno. Una vez lograda la calidad educativa, se puede pensar en dar a conocer esa calidad obtenida al entorno mediante la aplicación de técnicas de marketing, pero principalmente mediante el diseño de un plan de comunicación al exterior que ayude a mejorar la imagen que se tiene del centro. Una mejora de la imagen llevaría al aumento de las matriculaciones en el centro objeto del estudio.

Si bien los resultados de la aplicación del plan de mejora no se llegaron a analizar por no formar parte de la actividad académica de la maestría, se puede advertir que autores como Chaves (1996), Lambin (1995), Manes (2000, 2008), Martínez (2001) y Zapata (2000) respaldan la gestión de la imagen institucional mediante la utilización de planes de marketing basados en la ética. Estos planes están destinados a comunicar elementos tangibles e intangibles del centro tales como la infraestructura y el adecuado uso que se hace de ella con fines educativos, o la calificación de los docentes encargados de las diversas materias y su constante especialización.

El aporte de esta investigación a la gestión de la imagen de instituciones educativas consiste en la formulación de un instrumento para el Monitoreo del Cambio de Imagen (MCl) cuya aplicación cíclica permita a los centros trabajar en los elementos que se consideran clave para construir y mantener la percepción positiva en los usuarios y el entorno (véase Cuadro 13). La aplicación de este instrumento se basa en el desarrollo de cuatro etapas que diagnostican la situación de los elementos de la institución comprometidos, a fin de planear y aplicar correcciones. A su vez se supervisan las actividades que se desarrollan para mejorar dichos elementos, en especial en áreas tales como la comunicación, la documentación y la adaptación de la oferta educativa luego de aplicadas las evaluaciones pertinentes. Una vez desarrollado el primer ciclo del $\mathrm{MCl}$ se sugiere sea aplicado nuevamente con las correcciones oportunas.

De esta manera se logran realizar los cambios necesarios para una mejora de la imagen del centro, basados en las líneas de un instrumento adaptable a la realidad de cada centro educativo y su contexto.

\section{Conclusiones}

Si bien emitir una conclusión en un área donde hay poco camino recorrido parece arriesgado, es importante plantear algunas reflexiones para colaborar con la gestión adecuada de la imagen institucional de un centro educativo, cualquiera sea el contexto en que se encuentre el mismo.

Es oportuno determinar que los directores podrán utilizar para cambiar, sostener o apuntalar la imagen todos aquellos elementos de la organización que potencien los cambios hacia la mejora de la calidad educativa. El líder será el encargado de identificar los procesos internos que contribuyan a tal fin y de reconocer aquellos actores institucionales que sean capaces de actuar como agentes de cambio.

Los directivos han de ser capaces de definir qué herramientas son las más apropiadas, dado el contexto, para lograr comunicar de manera eficiente y eficaz la calidad educativa lograda, y de no contar con las capacidades requeridas deberán recurrir a asesores que puedan guiarlos en ese sentido. 
Cuadro 13. Instrumento para el Monitoreo del Cambio de Imagen

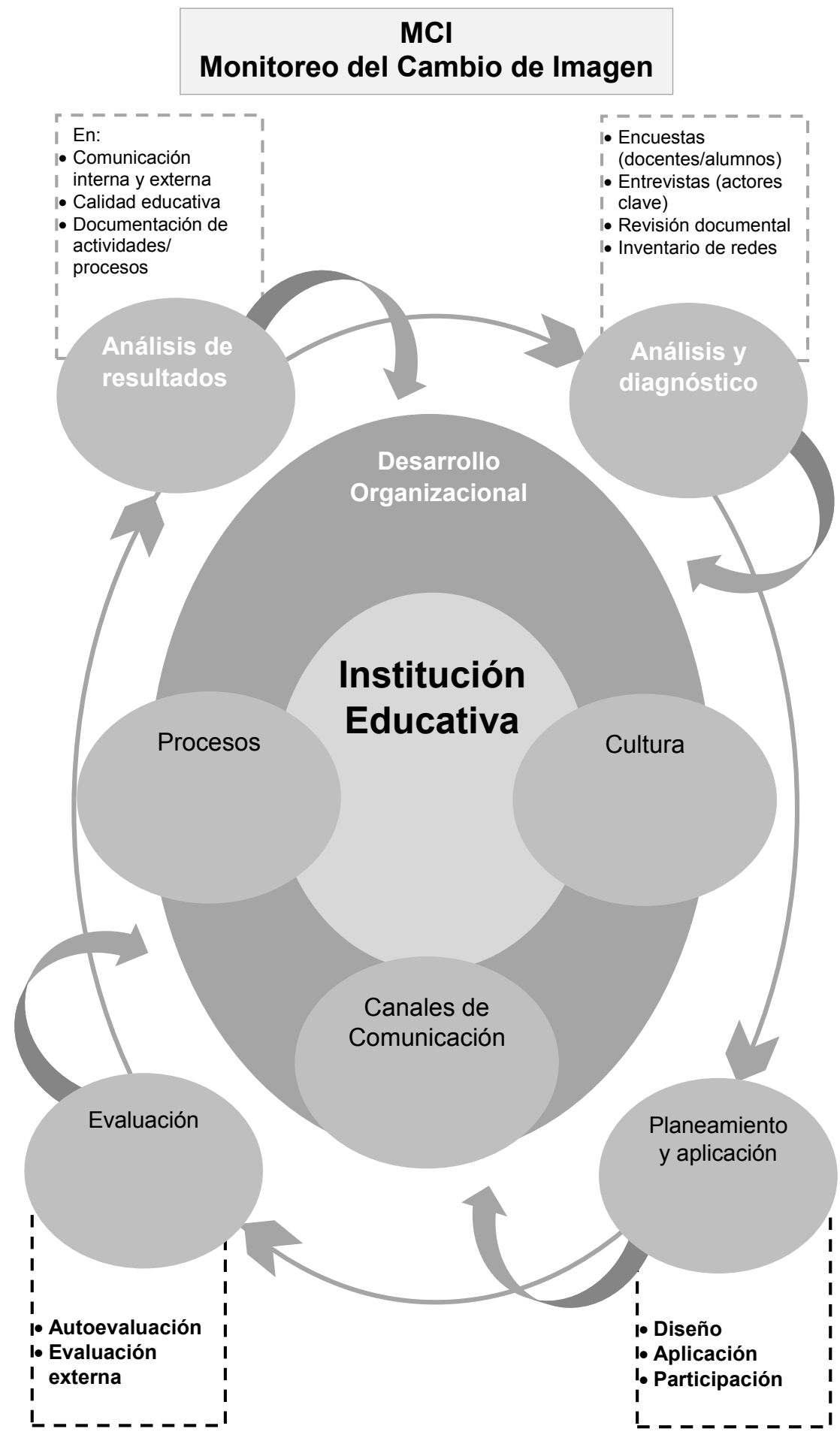


El diseño de un plan de mejora orientado al cambio de imagen será una pieza fundamental tanto de la gestión de procesos como del cambio de la cultura de la organización. En general, se propone el uso del Monitoreo del Cambio de Imagen $(\mathrm{MCl})$ que, dada su flexibilidad, es posible aplicar a cualquier institución educativa.

Sin embargo, las limitaciones de estudio consisten en que la aplicación del instrumento de monitoreo para comparar la fiabilidad y la pertinencia de los resultados obtenidos aún no se ha podido extender a otros centros de diferentes características. El estudio se basa en el caso de un centro privado de formación de carreras técnicas descentralizado, que es en el contexto uruguayo un área donde las estadísticas nacionales recién comienzan a esbozarse.

De poder realizarse la aplicación de este instrumento a una muestra de centros representativa de las distintas realidades nacionales o incluso regionales, podría demostrarse la utilidad del $\mathrm{MCl}$ para la inclusión en la agenda de los directivos del tema "imagen institucional", que llevaría no sólo a mejorar la percepción de un centro en particular por un contexto acotado, sino que sería una forma de lograr la adaptación de la educación a los alumnos con mentalidad y capacidades de este siglo, haciendo a la educación un objeto de deseo y motivación de los jóvenes educandos.

Así se podría responder de manera amplia a la pregunta formulada al principio de la investigación sobre la posibilidad de que la mejora de la imagen aumente la matrícula de un centro, a partir de la adecuación de la oferta educativa a las necesidades y mediante el desarrollo de una comunicación eficaz basada en el marketing y la ética.

Se espera que este artículo contribuya al debate sobre estas posibilidades.

\section{Bibliografía}

Bernal, J. (2008). Competencias de liderazgo. En J. Gairín \& S. Antúnez (Eds.), Las organizaciones educativas al servicio de la sociedad (pp. 151-155). Madrid: Wolters Kluwer España.

Bolívar, A. (2010). El liderazgo educativo y su papel en la mejora: una revisión actual de sus posibilidades y limitaciones. Psicoperspectivas. Individuo y Sociedad, 9(2), 9-33. Accedido el 15 de enero, 2014, desde www.psicoperspectivas.cl/index.php/psicoperspectivas/issue/view/13

Chaves, N. (1996). La imagen corporativa: teoría y metodología de la identificación institucional (3era ed.). México: Gili.

Covey, S. (2003). Los 7 hábitos de la gente altamente efectiva. La revolución ética en la vida cotidiana y en la empresa. (J. Piatigorsky, Trad.). Buenos Aires: Paidós. (Trabajo original publicado en 1989)

Covey, S. (2005). Los tres papeles que desempeña el líder en el nuevo paradigma. En F. Hesselbein, M. Goldsmith \& R. Beckhard (Eds.), El líder del futuro (pp. 177-188). (G. Hillers, Trad.). Buenos Aires: Deusto. (Trabajo original publicado en 1996)

Durán, M. (2004). Gestión del conocimiento e implicaciones para los centros escolares. En J. Gairín (Ed.), Gestión del conocimiento en red. Proyecto I+D+I, Ministerio de Educación y Ciencia, ref. SEC2003-08366 (documento no publicado).

Ewy, R. \& Gmitro, H. (2009). Process management in education. How to design, measure, deploy and improve educational processes. Accedido el 19 de febrero, 2014, desde http://books.google. com.uy/books/about/Process_Management_in_Education.html?id=PTYTqDEuzWYC\&redir_ esc $=y$

Frigerio, G., Poggi, M., Tiramonti, G. \& Aguerrondo, I. (1996). Las instituciones educativas. Cara y ceca. Elementos para su gestión (6ta ed.). Buenos Aires: Troquel. 
Gairín, J. (1998). Los estadios de desarrollo organizacional. Contextos educativos, 1, 125-154. Accedido el 27 de febrero, 2014, desde http://publicaciones.unirioja.es/ojs-2.4.2/index.php/ contextos/article/view/374

Gairín, J. (1999). La organización escolar: contexto y texto de actuación (2da ed.). Madrid: La Muralla.

Hargreaves, A. (2005). Profesorado, cultura y postmodernidad. Cambian los tiempos, cambia el profesorado (5ta ed.). (P. Marzano, Trad.). Madrid: Morata. (Trabajo original publicado en 1994)

Kotler, P. \& Armstrong, G. (2001). Marketing (8va ed.). (R. Escalona, Trad.). México: Pearson Educación. (Trabajo original publicado en 1999)

Kotter, J. (1997). El líder del cambio (P. Díaz, Trad.). México: McGraw-Hill Interamericana. (Trabajo original publicado en 1996)

Lambin, J. (1995). Marketing estratégico (3era ed.). (S. Miquel \& A. Cuenca, Trads.). Madrid: McGraw-Hill. (Trabajo original publicado en 1994)

Manes, J. (2000). Marketing educativo, gestión estratégica y calidad total: un círculo virtuoso. Organización y Gestión Educativa, 5, 3-8. Accedido el 28 de enero 2014, desde http:// temachtiani.ulsa.edu.mx/onteanqui/onteanqui3/presentaciones/marketing_manes.pdf

Manes, J. (2008). Marketing en instituciones educativas: guía para planificar la captación y retención de alumnos (2da ed.). Buenos Aires: Granica.

Marchesi, A. \& Martín, E. (1998). Calidad de la enseñanza en tiempos de cambio. Madrid: Alianza.

Martínez, F. (2001). Introducción al marketing educativo. Barranquilla: Uninorte.

Naranjo, C. (2011). Marketing educativo; desarrollo de una estrategia C.E.M. aplicado a la Universidad nacional de Colombia sede Manizales como base para la fidelización de clientes y complemento a la estrategia de C.R.M. (Tesis magisterial). Facultad de Administración, Universidad Nacional de Colombia. Accedido el 20 de enero, 2014, desde www.bdigital.unal. edu.co/3837/1/catalinanaranjohernandez.2011.pdf

Núñez, I. (2004). La gestión de la información, el conocimiento, la inteligencia y el aprendizaje organizacional desde una perspectiva socio-psicológica. Acimed, 12. Accedido el 27 de febrero, 2014, desde http://scielo.sld.cu/scielo.php?script=sci_arttext\&pid=S1024$94352004000300004 \&$ lng=es\&nrm=iso\&tlng=es

Parcerisa, A. (2008). Docencia y aprendizaje en la universidad: retos y dilemas. En J. Gairín y S. Antúnez (Eds.), Las organizaciones educativas al servicio de la sociedad (pp. 576-586). Madrid: Wolters Kluwer España.

Pérez, J. (2005). Los procesos y la gestión por procesos en educación: herramientas de mejora de los procesos. En F. González (Coord.), Gestión de calidad en la organización y dirección de centros escolares (pp. 65-81). Accedido el 7 de febrero, 2014, desde http://books.google. com.uy/books?id=TCgopizMwuEC\&pg=PA65\&lpg=PA65\&dq=los+procesos+y+la+gesti\%C3 $\% B 3 n+$ por+procesos+en+educaci\%C3\%B3n\&source=bl\&ots=xhV5zmk654\&sig=vWWXly47 YuratnNX6m9vqn0Zx28\&hl=es\&sa=X\&ei=Ow8QUbT9A4j09gT3gYHQDQ\&ved=0CDsQ6AE $w A w \# v=$ onepage $\& q \& f=$ false

Robbins, S. (2004). Comportamiento organizacional. Teoría y práctica. (10ma ed.). (J. Dávila \& R. Pescador, Trad.). México: Pearson Educación. (Trabajo original publicado en 2003) 
Rodríguez-Gómez, D. (2008). Gestión del conocimiento y otros procesos organizativos afines. En J. Gairín y S. Antúnez (Eds.), Las organizaciones educativas al servicio de la sociedad (pp. 136-143). Madrid: Wolters Kluwer España.

Santos, M. (2006). La escuela que aprende (4ta ed.). Madrid: Morata.

Vázquez, M. (2011). Procesos de cambio y autoevaluación en centros educativos. ¿Dos caras de una misma moneda? Barcelona: DaVinci.

Zapata, E. (2000). Mercadeo educativo ¿Cómo promover la oferta de instituciones y programas? Revista Colombiana de Marketing, 1(1). Accedido el 29 de enero de 2014, desde http://revistas. unab.edu.co/index.php?journal=marketing\&page=article\&op=view \&path\%5B\%5D=785 